\title{
A POLÍTICA AMBIENTAL PARA A REGIÃO DOS CAMPOS GERAIS DO PARANÁ
}

\section{The environmental policy in the region of the Campos Gerais of Paraná}

\author{
Isonel Sandino MENEGUZZO'
}

Edu Silvestre de ALBUQUERQUE ${ }^{2}$

\section{RESUMO}

O presente texto tem por premissa discutir as incoerências das políticas públicas voltadas à preservação e conservação da natureza nos Campos Gerais do Paraná. A região em questão apresenta características peculiares em razão do domínio fitogeográfico da vegetação de Campos (Estepe GramíneoLenhosa) com a ocorrência de Cerrado (Formação Savânica) e as matas de Araucária (Floresta Ombrófila Mista), inseridas numa paisagem historicamente marcada pela ocorrência de atividades agropecuárias. Entretanto, as políticas de conservação e preservação ambiental têm valorizado as áreas com remanescentes de florestas e de patrimônio natural cênico, em detrimento dos ecossistemas e da sustentabilidade do desenvolvimento das populações que habitam a região.

Palavras-chave: Política Ambiental; Campos Gerais do Paraná; Unidades de Conservação.

\begin{abstract}
This paper aims at discussing about public policies' inconsistencies related to preservation and conservation of nature in the Campos Gerais of Paraná. The region in question has peculiar characteristics due to presence the area with fields of vegetation (Grasslands Suffering Pine) with the occurrence of Brazilian savannah and the forests of Araucaria (Mixed Ombrophilus Forest), inserted in a landscape historically marked by agricultural activities. Meanwhile, policies of conservation and environmental preservation have valorized areas with remaining forests and from scenic natural heritage, in despite of ecosystems and sustainability and development of people who live in the region.
\end{abstract}

Keywords: Environmental Policy; Campos Gerais of Paraná; Units of Conservation.

AGRADECIMENTOS: Ao professor Ivan Meneguzzo (in memorian) pelas críticas construtivas em relação ao texto, pelos incentivos ao demonstrar sua preocupação com a degradação da paisagem dos Campos Gerais do Paraná e à Bióloga Adeline Chaicouski, pelo auxílio prestado na adequação do abstract e respectivos termos técnicos

1 Geógrafo, Mestre em Ciência do Solo pela UFPR e Professor Adjunto I do Centro de Ensino Superior dos Campos Gerais - CESCAGE. E-mail: imeneguzzo@hotmail.com

2 Geógrafo, Doutor em Geografia pela UFSC e Professor Adjunto do Departamento de Geociências da Universidade Estadual de Ponta Grossa - UEPG. E-mail: silvestre@uepg.br 
MENEGUZZO, I. S.; ALBUQUERQUE, E. S. de. A política ambiental para a região...

\section{INTRODUÇÃO}

Desde as últimas décadas do século passado discute-se a necessidade de mudanças no curso do desenvolvimento econômico de forma a incluir a preservação e a conservação do meio ambiente. Contudo, a efetivação deste paradigma ambiental passa por transformações profundas na estrutura material produtiva, exigindo abordagens que ultrapassem o plano da conscientização individual e das ações isoladas. Emerge, assim, a relevância do homem político ou ser social, capaz de reorientar/reinventar as políticas produtivas e ambientais no âmbito dos respectivos Estados nacionais e da governança global.

A política ambiental brasileira vigente adota como instrumento de gestão ambiental o Zoneamento Ecológico-Econômico (ZEE), que parte da proposta de articulação entre as esferas ambiental e produtiva, mas não toca na mudança da natureza da matriz produtiva. Desta forma, a política ambiental no território brasileiro encontra o obstáculo intransponível das condições produtivas mais gerais determinadas pelo mercado, regulado pela competição e pelo lucro.

A coerência da atual política ambiental brasileira baseada na articulação das diversas políticas produtivas (agrícola, florestal, mineral e energética) com impactos diretos no ambiente natural termina na impossibilidade de alteração da natureza predatória das políticas setoriais produtivas. Na prática, essa política ambiental de recorte transversal constitui antes uma engenharia econômico-ambiental complexa do que uma mudança real no sentido dos homens produzirem suas vidas a partir de matrizes econômico-ambientais mais equilibradas.

Nesse sentido, este artigo pretende discutir as incoerências da política ambiental brasileira a partir do estudo de caso de uma região do estado do Paraná, caracterizada pelo domínio de campos, vegetação de cerrado e de matas de araucária remanescentes.

Nos Campos Gerais do Paraná a produção social e técnica do ambiente natural se impõem por todas as partes, permitindo afirmar que a ação antrópica mediada pela técnica é uma constante histórica nesta região. Portanto, falar de natureza significa partir da noção de ambientes antropizados mesmo nos espaços de preservação e conservação.

Contudo, organizações ambientais e comunidades locais ainda esperam que a produção de uma natureza humanizada mais equilibrada na região ainda seja possível por meio da expansão das áreas de proteção ambiental, como por exemplo, através da formação de amplas áreas de transição com uso do solo regulamentado e de corredores ecológicos.

\section{A PAISAGEM DOS CAMPOS GERAIS DO PARANÁ}

No Paraná, a distribuição das áreas de campo, de uma forma genérica, cruza o estado no sentido sul-norte, sendo que nos Campos Gerais do Paraná a paisagem de campo dividia originalmente espaço com a Floresta Ombrófila Mista.

A expressão "Campos Gerais do Paraná" foi consagrada por Reinhard Maack (1950), ao defini-la como uma zona fitogeográfica de predomínio de campos, com a ocorrência de cerrados e matas ciliares ao longo dos rios e arroios e de capões isolados com a ocorrência do pinheiro de araucária, numa extensão original aproximada de $19.060 \mathrm{Km}^{2}$.

Os Campos Gerais estão localizados na porção leste do Segundo Planalto Paranaense, no reverso do degrau topográfico da Escarpa Devoniana (MELO; MENEGUZZO, 2001), apresentando suaves elevações de topo de planalto que se estendem desde Rio Negro, no limite com Santa Catarina, ao sul, até Sengés, no limite com São Paulo, ao norte.

Nas áreas de domínio de campos nos Campos Gerais fixou-se pioneiramente o luso-brasileiro em sistema de grande propriedade e criação bovina, contrastando com a ocupação das áreas de domínio de mata pelo imigrante europeu não ibérico no sistema de pequena propriedade. Ambos os modelos de uso do solo geraram processos de degradação do ambiente natural (processos de erosão hídrica, desmatamentos, queimadas e poluição hídrica) e de exclusão social (êxodo rural, favelização e miséria rural e urbana).

\section{OS DOMÍNIOS DE MATA}

A devastação é profunda nas áreas de mata presentes na região dos Campos Gerais do Paraná. A avidez da indústria madeireira provocou o desmatamento quase total das manchas de Floresta Ombrófila Mista ainda na primeira metade do século passado.

Esgotadas as reservas de madeira oriundas de mata primária, a atividade de reflorestamento foi estimulada. Inicialmente, a partir de incentivos fiscais do governo federal com a dedução de $50 \%$ no Imposto 
de Renda para pessoas jurídicas. Com a criação do Fundo de Incentivo Setorial, entre 1966 e 1987, é que se registra o primeiro período áureo dos investimentos no plantio de florestas. Neste momento, por exemplo, o Paraná plantou a maior área de pinus elliottii dentre os estados brasileiros ${ }^{3}$.

Dados do ano de 2000 indicavam que o Paraná alcançou cerca de 672 mil hectares de florestas plantadas, ainda contribuindo para o Sistema Estadual de Reposição Florestal Obrigatória, que exige dos consumidores paranaenses de matéria-prima florestal a obrigatoriedade de efetuar a reposição equivalente ao consumo (BRDE, 2003).

Desde a década de 1990 ocorre uma redução da importância dos incentivos fiscais e um crescimento dos investimentos diretos das grandes empresas de celulose e papel. Estima-se que mais de $75 \%$ das áreas plantadas nos últimos anos no país estejam vinculadas diretamente à indústria, percentual que tende a elevar-se principalmente com o desenvolvimento de projetos no sul do Brasil ${ }^{4}$. Infelizmente, seja no modelo florestal anterior baseado nos incentivos fiscais, seja no modelo atual baseado no investimento privado, persiste o descolamento entre as políticas florestais e as políticas ambientais propriamente ditas. A atividade florestal nos Campos Gerais tem sido sinônimo apenas de exploração madeireira!

\section{OS DOMÍNIOS DE CAMPO}

Atualmente o emprego do termo "meio natural" seria impróprio também às paisagens de campo em razão das sucessivas alterações produzidas na paisagem regional. A presença permanente de rebanhos bovinos desde o século XVIII até hoje tem representado forte pressão ambiental - produto da alimentação e pisoteio sobre os ecossistemas de campos da região, alterando a distribuição e a frequência das diversas espécies naturais de gramíneas. A rudimentar técnica da queimada para a renovação de pastagens é ainda hoje prática comum nas propriedades rurais da região. De acordo com Ziller (2000), é significativa a contaminação biológica por espécies fanerogâmicas exóticas, ameaçando a própria biodiversidade regional.

A instalação de grandes agroindústrias na região, principalmente a partir da década de 1970, representa outro divisor de águas em relação à questão ambiental, alterando novamente a paisagem e a biodiversidade dos campos naturais. Segundo o IBGE (1996), nos Campos Gerais do Paraná, as pastagens representavam em 1995 apenas $24,41 \%$ do solo utilizado contra $32,09 \%$ para as lavouras, o que bem atesta o avanço das culturas de grãos nas últimas décadas.

Daí se deduz a importância da conservação de amplas áreas de campos o menos impactadas possível, para que a vegetação e a fauna originais possam retomar seu espaço. Essa ideia já aparece em Klein (1978) e Moreira e Rocha (2007). Nesse sentido Moreira e Rocha (2007, p. 202) indicam que

As formações campestres do sul do Brasil têm despertado pouco interesse por parte das instituições ligadas ao estabelecimento das políticas e ações conservacionistas. Esta situação pode ser conseqüência da idéia errônea que os campos são formações homogêneas e pouco diversas.

Evidente que, para vastas áreas de campos com vegetação nativa deve-se pensar uma regulamentação específica de uso do solo para certas atividades econômicas. Mas, uma política ambiental para essa região não pode desconsiderar que também o homem que vive nesse ambiente passa por um profundo processo de desvalorização social. As elevadas taxas regionais de miséria urbana e rural são determinadas pelo excedente de trabalhadores em face da reduzida necessidade do processo produtivo local (LAROCCA JUNIOR, 2000) $)^{5}$.

3 O Grupo Klabin inicia suas atividades nos Campos Gerais ainda em 1934, com a aquisição de 144 mil ha de terras em Tibagi. Doze anos depois, construía fábrica no mesmo município utilizando-se de recursos do Banco do Brasil. Atualmente, o grupo é proprietário de 200 mil ha no município de Telêmaco Borba, desmembrado de Tibagi (PIQUET, 1998).

4 Ainda assim, o governo federal adota novos mecanismos de incentivo fiscal à atividade de florestamento a partir de 2002, como o PRONAF - Floresta (Programa Nacional de Fortalecimento da Agricultura Familiar), e o PROPFLORA (Programa para o Plantio de Florestas). O PRONAF - Floresta é gerido pelo Banco do Brasil, e libera recursos de até 6 mil reais para pequenos proprietários. O PROPFLORAé gerido pelo BNDES (Banco Nacional de Desenvolvimento Econômico e Social), e libera quantias de até 150 mil reais. O BRDE (Banco Regional de Desenvolvimento do Extremo Sul) opera em ambos como repassador de recursos aos produtores rurais.

5 Casseti (1999) demonstra a relação entre a consolidação de uma visão de natureza externalizada ao homem e a legitimação ideológica para o desenvolvimento das forças produtivas capitalistas. De fato, na perspectiva materialista a separação ideológica entre natureza e sociedade somente poderá ser plenamente superada quando emergir uma prática social capaz de alterar os fundamentos do sistema produtivo e das relações sociais de produção, para efetivamente romper aos indivíduos com os limites de horizonte impostos a partir da divisão capitalista da riqueza e da visão mercantil das relações sociais. 


\section{A POLÍTICA AMBIENTAL PARA OS CAMPOS GERAIS DO PARANÁ}

O papel regulador do Estado em relação ao meio ambiente é estratégico por contribuir no que tange a emergência do compromisso entre interesses múltiplos da sociedade, investidores e empresas (MORAES; TUROLLA, 2004), dentre outros atores formadores da agenda ambiental.

Pode considerar-se como marco da regulamentação de políticas ambientais no Brasil o momento da promulgação da Lei $n^{\circ}$. 6.938/81 que estabelece a Política Nacional de Meio Ambiente. Posteriormente, destaca-se o Código Florestal Brasileiro de 1965 e a Constituição Federal de 1988, onde o Estado tem a função de promover a conservação, a fiscalização e a gestão ambiental.

As políticas ambientais no Brasil se desenvolveram de forma tardia se comparada com outras políticas públicas, e, basicamente em resposta às exigências do movimento ambientalista internacional (SOUSA, 2005). Os aspectos econômicos foram os fatores norteadores das políticas nesta área, visando fundamentalmente corrigir problemas oriundos de atividades industriais e agrícolas e controlar a poluição ambiental. Daí a intervenção pública na área ambiental caracterizar-se inicialmente pela utilização de instrumentos financeiros (taxação, subsídios, mercados de direitos de uso) e normas e regulamentos específicos (MORAES; TUROLLA, 2004).

Esse quadro se repete nas políticas ambientais concebidas no Estado do Paraná, voltadas basicamente à criação de unidades de conservação e de legislação reguladora do uso do solo e da água.

Na prática, ainda não há no estado uma integração dessas políticas ambientais com as políticas setoriais produtivas geradoras de impactos ambientais, nem mesmo quando o impacto ambiental é evidente como no caso das atividades de (re)florestamento. A raiz desse problema parece residir na abordagem de conservação ambiental do tipo enclave. Com efeito, nos Campos Gerais do Paraná existem, sob a égide da legislação ambiental, as seguintes Unidades de Conservação (Tabela 1):

- Parque Estadual de Vila Velha (Ponta Grossa): embora a área possua importantes manchas de campos limpos e formações florestais que ainda mantêm suas características primárias, é a preservação da beleza cênica proporcionada por suas formações areníticas peculiares o principal objetivo do parque.

- Parque Estadual do Guartelá (Tibagi): Embora apresente no topo áreas de savana com enclaves de cerrado sua criação deveu-se à preservação do fundo de vale, que forma um dos maiores canyons do mundo.

- Parque Estadual Córrego da Biquinha (Tibagi): Predomínio absoluto da floresta ombrófila mista e mata secundária (75\%) (PARANÁ, 1999).

- Parque Estadual Floresta do Saltinho (Imbaú): A formação vegetacional predominante é composta de capoeira remanescente da floresta com araucária (PARANÁ, 1999).

- Parque Estadual do Cerrado (Jaguariaíva): Uma das poucas áreas de preservação da região formada predominantemente por formas savânicas que variam do campo limpo a campo sujo, passando pelo campo cerrado, cerrado sensu stricto até o cerradão (TAKEDA; MATTOSO TAKEDA; FARAGO, 2001).

- Parque Estadual do Monge (Lapa): Ainda que apresente áreas de mata alteradas e reflorestamentos, abrange uma região de campos limpos, os chamados Campos da Lapa, com capões associados a florestas de galeria profundamente antropizados (MOREIRA; ROCHA, 2007). Entretanto, em sua criação também foram considerados os atrativos naturais da Gruta do Monge e da cachoeira da Pedra Partida.

A ideia de enclaves ambientais chegou também aos municípios da região, implantando unidades de conservação através de legislação própria:

- Parque Municipal de Palmeira (Palmeira): A área pertence ao bioma de floresta com araucária.

- Parque Municipal São Domingos (Tibagi): Domínio da floresta ombrófila mista.

- Parque Municipal Lago Azul (Jaguariaíva): Domínio da floresta estacional semidecidual.

- Parque Municipal Mata Boca da Ronda (Ponta Grossa): Localizado na área urbana do município supracitado, a cobertura vegetal caracteriza-se por uma associação secundária de Floresta Ombrófila Mista com capoeiras 
MENEGUZZO, I. S.; ALBUQUERQUE, E. S. de. A política ambiental para a região....

(TAKEDA; MATTOSO TAKEDA; FARAGO 2001).

- Parque Municipal Margherita Masini (Ponta Grossa): Igualmente localizado na área urbana de Ponta Grossa e constituída pela associação secundária da floresta ombrófila mista com a introdução de espécies exóticas (TAKEDA; MATTOSO TAKEDA; FARAGO, 2001).

- Horto Florestal Geraldo Russi (Tibagi): A formação vegetal é constituída basicamente de vegetação natural composta de capoeira muito pobre (TAKEDA; MATTOSO TAKEDA; FARAGO, 2001) e reflorestamento com Pinus elliottii que substituem a floresta primitiva e floresta pluvial subtropical com araucária.

Diante do elevado grau de miséria no campo e nas cidades dos Campos Gerais do Paraná, o alegado potencial turístico do patrimônio natural dentro e fora dos parques da região não parece promissor.
Também é fácil notar que essas unidades de conservação foram pensadas fundamentalmente para proteger áreas remanescentes de biomas de florestas ou áreas de patrimônio natural para fins de ecoturismo, e apenas secundariamente para proteção das áreas de ecossistemas de campo que formam o domínio predominante da região dos Campos Gerais. Esse modelo de conservação da biodiversidade através da criação de parques (áreas protegidas) segue a concepção norteamericana de reservas. Para Sarkar (2000, p. 47):

Em âmbito global, a ação potencialmente mais relevante foi a adoção da Convenção sobre Diversidade Biológica das Nações Unidas, na Conferência do Rio de Janeiro, em junho de 1992. Em âmbito local, as respostas variaram desde o pequeno, porém muito exitoso, Santuário Comunitário de Proteção ao Babuíno de Belize, de propriedade e manejo privado com fins lucrativos por meio do turismo, até os gigantes parques nacionais dos Estados Unidos, mantidos com custos consideráveis aos contribuintes.

TABELA 1 - UNIDADES DE CONSERVAÇÃO NOS CAMPOS GERAIS DO PARANÁ

\begin{tabular}{|c|c|c|c|c|}
\hline $\begin{array}{c}\text { Grupo de } \\
\text { Manejo (Cf. } \\
\text { SNUC, 2000) }\end{array}$ & $\begin{array}{l}\text { Categoria da } \\
\text { Unidade de } \\
\text { Conservação }\end{array}$ & $\begin{array}{l}\text { Unidade de } \\
\text { Conservação }\end{array}$ & $\begin{array}{l}\text { Área } \\
\text { (ha) }\end{array}$ & Município \\
\hline \multirow{13}{*}{$\begin{array}{l}\text { Proteção } \\
\text { Integral }\end{array}$} & \multirow{6}{*}{ Parque Estadual } & Vila Velha & 3.803 & Ponta Grossa \\
\hline & & Guartelá & 790 & Tibagi \\
\hline & & Cerrado & 420 & Jaguariaíva \\
\hline & & Gruta do Monge & 298 & Lapa \\
\hline & & Córrego da Biquinha & 23,22 & Tibagi \\
\hline & & $\begin{array}{c}\text { Estadual Floresta } \\
\text { do Saltinho }\end{array}$ & 9,10 & Imbaú \\
\hline & Parque Nacional & Campos Gerais & 21.288 & $\begin{array}{c}\text { Ponta Grossa } \\
\text { Castro e Carambeí }\end{array}$ \\
\hline & $\begin{array}{l}\text { Reserva Biológica } \\
\text { (Nacional) }\end{array}$ & Araucárias & 14.920 & Teixeira Soares, Imbituva e Ipiranga \\
\hline & \multirow{5}{*}{ Parque Municipal } & Palmeira & 45,90 & Palmeira \\
\hline & & São Domingos & 54,45 & Tibagi \\
\hline & & Lago Azul & 11,97 & Jaguariaíva \\
\hline & & $\begin{array}{l}\text { Mata Boca } \\
\text { da Ronda }\end{array}$ & 3,81 & Ponta Grossa \\
\hline & & Margherita Masini & 5,86 & Ponta Grossa \\
\hline
\end{tabular}


MENEGUZZO, I. S.; ALBUQUERQUE, E. S. de. A política ambiental para a região...

\begin{tabular}{|c|c|c|c|c|}
\hline $\begin{array}{c}\text { Grupo de } \\
\text { Manejo (Cf. } \\
\text { SNUC, 2000) }\end{array}$ & $\begin{array}{l}\text { Categoria da } \\
\text { Unidade de } \\
\text { Conservação }\end{array}$ & $\begin{array}{l}\text { Unidade de } \\
\text { Conservação }\end{array}$ & $\begin{array}{l}\text { Área } \\
\text { (ha) }\end{array}$ & Município \\
\hline \multirow{7}{*}{ Uso Sustentável } & \multirow{2}{*}{ Floresta Nacional } & Pirai do Sul & 276 & Piraí do Sul \\
\hline & & Irati & 3.495 & Teixeira Soares e Fernandes Pinheiro \\
\hline & \multirow{2}{*}{ Floresta Estadual } & Passa Dois & 171 & Lapa \\
\hline & & $\begin{array}{l}\text { Floresta Estadual } \\
\text { Córrego da Biquinha }\end{array}$ & 23,22 & Tibagi \\
\hline & $\begin{array}{c}\text { Área de Proteção } \\
\text { Ambiental (Estadual) }\end{array}$ & Escarpa Devoniana & 392.336 & $\begin{array}{c}\text { Jaguariaíva, Lapa, Porto Amazonas, } \\
\text { Castro, Ponta Grossa, Tibagi, Sengés, } \\
\text { Piraí do Sul, Palmeira e Balsa Nova }\end{array}$ \\
\hline & Horto Florestal & $\begin{array}{l}\text { Horto Florestal } \\
\text { Geraldo Russi }\end{array}$ & 130,80 & Tibagi \\
\hline & Reserva Florestal & $\begin{array}{l}\text { Reserva Florestal } \\
\text { de Saltinho }\end{array}$ & 9,10 & Telêmaco Borba \\
\hline Área total & & & 438.114 & \\
\hline
\end{tabular}

FONTE: IAP (2008), modificado de Moreira; Rocha (2007).

\section{A NOVA GERAÇÃO DE POLÍTICAS AMBIENTAIS: ZEE'S E APA'S}

A implantação do Zoneamento Ecológico-Econômico (ZEE) faz parte de uma nova geração de políticas públicas ambientais, com enfoque no paradigma do desenvolvimento sustentável, ou seja, articulando a questão ambiental com a racionalização do uso do solo e desenvolvimento econômico. O zoneamento ambiental nasce como instrumento da Política Nacional do Meio Ambiente através da Lei Federal $n^{\circ}$. 6.938, de agosto de 1981 (BRASIL, 2002a). Mas os critérios para o Zoneamento Ecológico-Econômico do Brasil são determinados apenas pelo Decreto $n^{\circ}$. 4.297, de julho de 2002.

O ZEE do Estado do Paraná está sendo elaborado pelo Instituto de Terras, Cartografia e Geociências (ITCG), vinculado à Secretaria Estadual de Meio Ambiente (SEMA), e discutido com representantes das sociedades locais (previsto para ser concluído em 2010). Veiga (2001, p. 205) comenta que "Desta forma, o ZEE, muito mais do que um estudo das condições físicas e socioeconômicas da microrregião, será um instrumento de negociação e de ajuste entre as diversas visões locais sobre o seu desenvolvimento".

No tocante aos corredores ecológicos, a própria lei que o define já faz parte do que aqui chamamos de políticas ambientais de nova geração. Em Brasil (2002b, p. 168), os corredores ecológicos são definidos como:

porções de ecossistemas naturais ou seminaturais, ligando unidades de conservação, que possibilitam entre elas o fluxo de genes e o movimento da biota, facilitando a dispersão de espécies e a recolonização de áreas degradadas, bem como a manutenção de populações que demandam para sua sobrevivência áreas com extensão maior do que aquela das unidades individuais.

Contudo, a participação social que precede o ZEE do Paraná não significa por si só que a meta de desenvolvimento sustentável será atingida. Visando romper com a ideia de enclaves vegetacionais e com o escopo de fomentar corredores ecológicos, o Ministério do Meio Ambiente (MMA) criou entre 2005 e 2006 cinco novas UC's federais no Paraná, incluindo o Parque Nacional dos Campos Gerais (PNCG) e a Reserva Biológica das Araucárias:

- Parque Nacional dos Campos Gerais (Ponta 
Grossa, Castro e Carambeí): associação entre floresta com araucária e campos nativos, além de grande potencial cênico, incluindo afloramentos de rochas ao longo da Escarpa Devoniana (MOREIRA; ROCHA, 2007).

- Reserva Biológica das Araucárias (Teixeira Soares, Imbituva e Ipiranga): associação entre floresta de araucária, florestas de várzea e campos nativos (MOREIRA; ROCHA, 2007).

Existe ainda outra exceção ao modelo ambiental de enclaves. Em zona de transição entre os compartimentos geomorfológicos do Primeiro e do Segundo Planalto Paranaense foi implementada em forma de Lei a Área de Proteção Ambiental (APA) denominada "Escarpa Devoniana", que abrange aproximadamente 392 mil hectares de área de transição entre os planaltos supracitados, inclusive faixa de Campos Gerais (TAKEDA; MATTOSO TAKEDA; FARAGO, 2001). A APA da
Escarpa Devoniana engloba as áreas do Parque Estadual de Vila Velha, Parque Estadual do Monge, Parque Estadual do Cerrado e Parque Estadual do Guartelá (MOREIRA; ROCHA, 2007).

A ideia das APA's poderia auxiliar a resolver a questão da conservação dos últimos remanescentes da floresta de araucárias e da manutenção do fluxo gênico entre estas (MOREIRA; ROCHA, 2007). Mas, na prática, não se observam mudanças profundas no uso do solo nesta vasta região que deveria ser de preservação e conservação, não apenas pela vastidão da área para fins de fiscalização ambiental, mas pela própria natureza do processo econômico que continua valorizando essas terras exclusivamente pelo potencial mercadológico e impelindo seus moradores a continuarem a buscar sua reprodução através de formas econômicas predatórias, como o uso intensivo do solo para fins agrícolas, por exemplo.

\section{CONSIDERAÇÕES FINAIS}

A região dos Campos Gerais do Paraná apresenta ecossistemas com características peculiares em razão do domínio da vegetação de campos, dos cerrados e das matas de araucária. As políticas públicas de conservação e preservação ambiental são genéricas e não o contemplam com especificidade.

A título de exemplificação cita-se o Código Florestal Brasileiro, o qual faz menção à vegetação de campos de forma genérica, englobando todas as formações vegetacionais brasileiras. Ressalta-se que nem todos os campos estão sobre uma formação geológica constituída de arenitos, com solos litólicos, cambissolos e latossolos, sob o domínio climático do tipo Cfb (de Köppen), sobre um relevo contrastante com feições que variam desde colinas alongadas até profundos canyons como o do Rio lapó entre os municípios de Castro e Tibagi.

Deveria, em caráter de urgência, serem ampliadas as áreas de preservação dos ecossistemas de campos, e também pensada sua articulação através da interligação por corredores ecológicos levando-se em consideração critérios técnicos. Característica ate- nuante, a pecuária e o (re)florestamento de pinus e de eucalipto desenvolvem-se ainda com forte vinculação ao ritmo da natureza, o que poderia ser um fator melhor aproveitado nas políticas ambientais para os Campos Gerais do Paraná, quando se sabe que são atividades econômicas importantes na região. Seria interessante, por exemplo, que o ZEE considerasse para as áreas de transição das unidades de conservação existentes o (re)florestamento incluindo espécies típicas de Floresta Ombrófila Mista incluindo a preservação de campos.

Os corredores ecológicos seriam formados ainda por áreas de matas ciliares remanescentes e recompostas, pensando-se em formas indenizatórias para os proprietários lindeiros. Entretanto, as políticas ambientais do tipo enclave ou tipo ZEE ainda não contemplam suficientemente o "homem campeiro" e suas necessidades.

A regulação da atividade privada geral a partir de uma real simbiose entre políticas setoriais produtivas e políticas ambientais, parece que ainda necessitará aguardar outra geração de políticas públicas. 
MENEGUZZO, I. S.; ALBUQUERQUE, E. S. de. A política ambiental para a região...

\section{REFERÊNCIAS}

BRASIL. Política Nacional do Meio Ambiente. In: ROCCO, R. Legislação brasileira do meio ambiente. Rio de Janeiro: DP\&A Editora, 2002a. p. 85-97.

BRASIL. Sistema Nacional de Unidades de Conservação da Natureza. In: ROCCO, R. Legislação brasileira do meio ambiente. Rio de Janeiro: DP\&A Editora, 2002b. p. 166-186.

BRDE. Florestamento na Região Sul do Brasil. Disponível em: <www.brdr.com.br/>. Acesso em: 16/9/2003.

CASSETI, V. Contra-correnteza. Goiânia: Kelps, 1999. $139 p$.

CERVI, A. C.; HATSCHBACH, G. Flora. In: ROCHA, C. H.; MICHALIZEN, V.; PONTES FILHO, A. Plano de Integração do Parque Estadual Vila Velha - Rio São Jorge. Ponta Grossa: Ituphava S/C e Prefeitura Municipal de Ponta Grossa, 1990.

IAP. Instituto Ambiental do Paraná. Disponível em: <www.iap. pr.gov.br/>. Acesso em: 05/2/2008.

IBGE. Censo Agropecuário 1995-1996. Rio de Janeiro: IBGE, CD-ROM. 1996.

KLEIN, R. M. Mapa fitogeográfico do estado de Santa Catarina. Itajaí: Herbário Barbosa Rodrigues/ Flora llustrada. Catarinense/ SUDESUL/FATMA, 1978. 24p.

LAROCCA JUNIOR, J. Desenvolvimento industrial em Ponta Grossa (PR): avaliação e perspectivas. 210p. Dissertação (Mestrado em Economia) - Universidade Federal de Santa Catarina, Florianópolis, 2000. 189p.

MAACK, R. Notas preliminares sobre clima, solos e vegetação do Estado do Paraná. Boletim Geográfico, Rio de Janeiro, ${ }^{\circ}$ 84 , p. 1401-1487, 1950.

MELO, M. S.; MENEGUZZO, I. S. Patrimônio natural dos Campos Gerais do Paraná. In: DITZEL, C. H. M.; LÖWEN SAHR, C. L. Espaço e Cultura: Ponta Grossa e os Campos
Gerais. Ponta Grossa: Editora da UEPG, 2001. cap. 23, p. 415-428.

MORAES, S. R. R.; TUROLLA, F. A. Visão geral dos problemas e da política ambiental no Brasil. Informações Econômicas, São Paulo, n. 4, p. 7-13, abr. 2004.

MOREIRA, J. C. ; ROCHA, C. H. Unidades de Conservação dos Campos Gerais. In: MELO, M. S.; MORO, R. S; GUIMARÃES, G. B. Patrimônio Natural dos Campos Gerais do Paraná. Ponta Grossa: Editora UEPG, 2007, cap. 8, p. 201-212.

PARANÁ. Unidades de Conservação do Estado do Paraná. Curitiba: SEMA/IAP, 1999.

PIQUET, R. Cidade-empresa. Rio de Janeiro: Zahar, 1998. $166 \mathrm{p}$.

SARKAR. Etnoconservação da natureza: enfoques alternativos. In: DIEGUES, A. C. Etnoconservação: novos rumos para a proteção da natureza nos trópicos. 2. ed. São Paulo: Hucitec/ Annablume/Nupaub.USP, 2000. cap. 2, p. 47-66.

SOUSA, A. C. A. A evolução da política ambiental no Brasil do século XX. Revista de Ciência Política, Rio de Janeiro, $\mathrm{n}$. 30, p. 21-25, 2006.

TAKEDA, A. K.; MATTOZO TAKEDA, I. J. M.; FARAGO, P. V. Unidades de conservação da região dos Campos Gerais, Paraná. Revista Publicatio, Ponta Grossa, v. 7, n.1, p. 57-78, 2001.

VEIGA, J. E. Desenvolvimento Territorial: do entulho varguista ao zoneamento ecológico-econômico. Análise \& dados, Salvador, v. 10, n. 4, p. 193-206, 2001.

ZILLER, S. R. A estepe gramíneo-lenhosa no Segundo Planalto do Paraná: diagnóstico ambiental com enfoque à contaminação biológica. 2000. 285 p. Tese (Doutorado em Engenharia Florestal) - Setor de Ciências Agrárias, Universidade Federal do Paraná, Curitiba, 2000. 